\title{
Fragmentation of the Thinking Structure of Translation in Solving Mathematical Modelling Problems
}

\author{
Kadek Adi Wibawa \\ Program Studi Pendidikan Matematika FKIP Universitas Mahasaraswati Denpasar, Bali, \\ Indonesia \\ adiwibawa@unmas.ac.id
}

\begin{abstract}
Fragmentation of the thinking structure is the process of construction of information in the brain that is inefficient, incomplete, and not interconnected, and hinders the process of mathematical problem solving. In solving mathematical modeling problems, students need to do translation thinking which is useful for changing the initial representation (source representation) into a new representation (target representation). This study aims to discover how the occurrence of the fragmentation of the thinking structure of translation within students in their solving of mathematical modeling problems. The method used is descriptive qualitative with the instrument in the form of one question for the mathematical modeling of necklace pendants and semi-structured interview sheets. The results showed that there were three errors that occurred in solving mathematical modeling problems. First, the error in changing a verbal representation to a graph. Secondly, errors in changing a graphical representation to symbols (algebraic form). Thirdly, errors in changing graphical representation and symbols into mathematical models. The three errors that occur are described based on the four categories of Bosse frameworks (Bosse, et al., 2014), namely: (1) unpacking the source (UtS), (2) preliminary coordination (PC), (3) constructing the target (CtT), and (4) determining equivalence (DE). In this study, there were 3 subjects who experienced fragmentation of the thinking structure in solving mathematical modeling problems. One of the highlights is the fragmentation of the structure of translation thinking often starts from the process of unpacking of the source due to the incompleteness of considering all the available source details.
\end{abstract}

Keywords: Fragmentation of thinking structure, translation process, problem solving, mathematical modelling.

\section{Introduction}

In solving mathematical modeling problems, students often experience difficulties and produce wrong answers (Kiat, 2005; Yost, 2009; Dorko, 2011; and Serhan, 2015). Complex problems require variations in ideas, strategies and the mathematical formulations used. This results in students having to think hard in order to arrive at the right answers and in accordance with the problems at hand. Difficulties are often the first thing experienced and felt by students, because the solution to the problems encountered is not immediately known by using ordinary procedures. This situation has been studied by several researchers such as Kiat (2005), Yost (2009), Zakaria, et al. (2010), Dorko (2011), Wibawa (2013), Booth, et al. (2014), Subanji (2015); Veloo, et al. (2015), and Serhan (2015). The research that has been done only identifies errors that occur through the work of the students. The studies carried out have not yet arrived at the discovery of the sources of errors through the disclosure of the students' thinking processes in solving mathematical problems. Kiat (2005) reveals that there are three types of 
errors in solving mathematical problems, (1) conceptual errors, (2) procedural errors, and (3) technical errors (technical errors). In this case Kiat (2005) has not traced the thinking processes of students who experience errors therefore it is necessary to do further research related to how students think when solving mathematical problems. In particular, Serhan (2015) stated that there is a need for further research to investigate students' thinking processes when solving mathematical problems.

In the process of solving the problems of mathematical modeling, the structure of thinking that is formed through difficulties and errors that occur, often seems like it is not organized and not well connected (Skemp, 1976, 2006). In this case, Skemp (1976, 2006) describes it as an instrumental understanding, which is described as separate (unconnected) ideas (procedural) without meaning. The term without meaning means that a person does not understand well the concepts that have been learned, cannot relate them to other concepts so as to give rise to an incomplete understanding. Conditions like this lead to separate or poorly connected ideas. Ideas without meaning can also result in the idea is stored in the memory (because it has been learned) but is forgotten accidentally over time (Sternberg, 2012). For example: when a student encounters a problem to determine an integral form of a mathematical model of a rotating object, the student is unable to reveal and associate all the components related to it. In fact, students have studied it during high school and in the previous semester which shows material that while it has been stored in memory it is forgotten accidentally over time. Someone who learns new concepts without meaning, the concept is stored in a separate structure.

Wahono (2009) stated that in the learning process, when students receive information in the form of concepts, procedures, and others, actually the student manages to construct what was taught. But there are those that are well constructed (concepts are understood in their entirety [Editors note: Neuro researchers calls this the long-term memory]) and some that are not well constructed (concepts are not fully understood). The information conditions that are not fully understood, according to Wahono (2009) results in the information being not well connected or "messy" (unorganized). Wahono (2009) called it a fragmentation in the student's storage system.

The term fragmentation is very popular in the computer world which is defined as the condition of a file that is placed in a storage system that does not occupy the sector (storage space) efficiently. Subanji (2016) stated that fragmentation of computers is interpreted as a phenomenon in storage space that is used inefficiently, reducing storage capacity. Fragmentation occurs when the operating system cannot allocate enough space in adjacent storage sectors to store files in a neat structure. This happens because someone often deletes files and then adds them again with files of the same size and type. Fragmentation results in system work delays in calling stored data or data that has been constructed.

The process of changing representations, from the initial representation (source representation) to the new representation (target representation) is called translation (Bosse et al. 2014). In this study, the making of a mistake with the new representation from a previously correctly made representation is called a translation error. The process of cognition that occurs can be observed through the results of the interviews (think aloud) and the results of student work. The students' cognition processes in translating can be recorded through self-reports by students of their thinking. The wrong pattern of students' thinking structure is called the 
fragmentation and are not organized, are separate and are not interconnected. In this case, structural fragmentation is fragmentation of the structure of translational thinking.

The process of the fragmentation of the structure of translation thinking in terms of the framework created and used by Bosse, et al. (2014), includes: (1) unpacking the source (UtS), (2) preliminary coordination (PC), (3) constructing the target (CtT), and (4) determining equivalence (DE):

1. Unpacking the source or dismantling the source representation is defined as reading and considering the concepts that exist in the re-presentation of the source (often called the micro concept) used to build the plan for making a target representation.

2. Preliminary coordination is defined as identifying and typing the same mathematical relationships between micro concepts in source representations and micro concepts in target representations.

3. Constructing the target (representation) is defined as formulating and making target representations based on the micro concepts that exist in the source representation and planned coordination.

4. Determining equivalence or equality is defined as re-structuring the target representation or re-checking the similarity of ideas that are in accordance with the rules of the source representation.

The idea of building new representations or translating is mentioned because there are gaps between existing facts or fact gaps (Bosse et al. 2014). In the construction process, which is seen from the occurrence of structural fragmentation, thinking that the translation occurs, the fact gaps can be seen as a scheme of gaps (SG) or gap between schemes. The gap or nonconformity that occurs is one reason students make new representations or restructure the representations that have been made.

In this study, the focus was on how the fragmentation structure of translation thinking occurred in students in solving mathematical modeling problems. The translation process is important in solving mathematical modeling problems. Students need to do translations ranging from verbal to pictures, graphics to graphics, verbal to algebraic forms, algebraic forms and pictures to mathematical models. There are still many students who experience difficulties and make mistakes in doing translation thinking.

\section{Methodology}

The method used was descriptive qualitative and used an instrument in the form of one question and semi-structured interview sheets for the mathematical modeling of necklace pendants. The data collected in this study are words or sentences so that the results of this study are descriptive data. Data analysis in this study is inductive because the data analysis activities use facts from the field and the results of 'think aloud' reports to find the process of translational structure fragmentation in solving mathematical modeling problems (involving integral applications of the volume of rotating objects). According to Creswell (2007), Bogdan and Taylor (in Moleong, 2007), and Yin (2011), this kind of research is classified as qualitative research.

This research was carried out in the Mathematics Education Study Program, FMIPA, State University of Malang for even semester students in 2014 and 2015 (Semesters 4 and 6). 
Researchers chose mathematics education students: who had learned integral concepts since high school and re-studied them in lectures (according to the syllabus of integral application material on the volume of rotary objects taught in semester 2); were assumed to have a more complete and in-depth thinking structure so that the exploration process carried out by the researchers by tracing the fragmentation of the structure of thinking became more visible. This also makes it easier for researchers to adapt various ways of structuring when students experience difficulties or are wrong in solving the problems given.

In accordance with the preliminary study, in this study students' answers are grouped into 3 categories: (1) Students with very essential errors are not aware of an "irregular" build or curved residual space, (2) Students with essential errors are aware of an "irregular" building or a curved space but do not use integrals to solve them, and (3) students with essential errors where they are aware of irregular builds or curved spaces and use integrals in the course of solving the problem but the answer given is wrong. Researchers conducted a study on 83 students who were divided into three further categories, three subjects in this study were selected for each category.

Initially, 83 students were given problems in the form of mathematical modeling problems to calculate the volume of a rotating object. Student answers are grouped as right and wrong answers. Correct answers are not used in this study because the focus of the study is to uncover and observe the fragmentation of thinking structures that begin with an error. Student answers that are wrong are grouped according to three categories that have been made. Percentage of each group namely: there were 63 students (75.90\%) who answered as described in category 1, the distribution of 32 students (38.55\%) from semester 4, and 31 students $(37.35 \%)$ from the semester 6 . For students who answered as described in category 2 , there were 17 students $(37.35 \%)$ and all were semester 6 students. In category 3, there were 3 students $(3.62 \%)$ who answered as description and these 3 students from semester 6 . Students in each category are further investigated through the interview stage. Through interviews conducted with students (prospective subjects), researchers revealed the existence of fragmented thinking structures. Interviews were conducted with the snowball sampling method, by calling one student at a time according to the three categories. Students who experienced fragmentation of translational thinking structures are students who make mistakes in constructing target representations from known and understood source representations.

\section{Result and Discussion}

In this study, students experience errors in making new representations of previously made representations, with the aim of solving problems they have encountered. The representation in question is an external object in the forms of graphs, symbols (algebraic forms), words (situations), and mathematical models that function as coding symbols. They describe the mathematical relationships or ideas and communicate the mathematical knowledge and operate on the mathematical constructions (Cobb, et al. 1992; Kaput, 1987). The new representations made by the first student was in the form of graphs or drawings on the Cartesian diagram. The image aimed to facilitate the student in determining the equation. The second new representation was in the form of symbols or algebraic forms which aimed to facilitate the student to determine the mathematical models or integral forms. The third new 
representation was in the form of a mathematical model or integral form which aimed to facilitate the student to determine the remaining volume. Each of the representations made by the students revealed errors which resulted in the students having difficulty continuing their work and creating other errors in determining the final answer.

This study found three types of structural fragmentation of translation thinking, namely, fragmentation of translation structure thinking from verbal to graphical, from graphical to symbolical (algebraic form), and from graphical and symbolical to mathematical models (integral forms). The mathematical modeling problem is given below:

\begin{abstract}
A company wants to produce the latest gold necklace with two solid ball-shaped beads that look like picture 1 below. To make these beads a hole must be punched through the beads diametrically using a drill bit of $5 \mathrm{~mm}$. For aesthetic purposes, the radius of a solid ball is determined as twice the radius of the drill bit. This company wants to know how much gold is remaining in the 2 beads in the necklace (before being carved). Can you help this company to solve it?
\end{abstract}

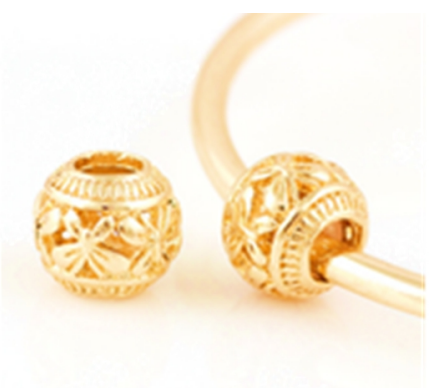

Picture 1: The beads

\title{
Fragmentation of Translations Thinking Structure from Verbal to Graphics
}

Students are aware of the fragmentation of the structure of translational thinking after researchers invite students to reflect by providing limited interventions. An illustration of the process that occurs is as shown in figure 1 below.

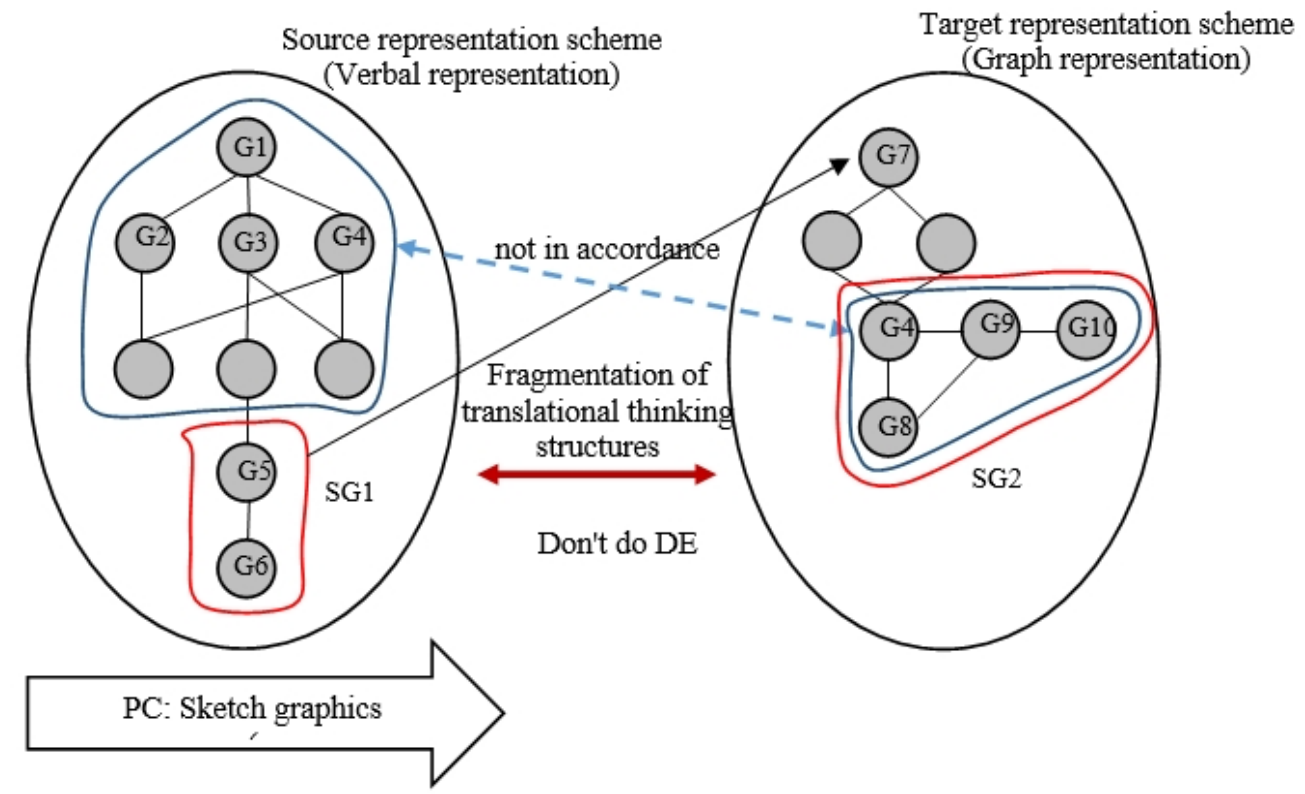


Figure 1. Illustration of Fragmentation of Translation Thinking Structure from Verbal to Graphical Representation.

Students initially understand that the problem faced is the problem of a ball being drilled (G1). The results of this drilling are partitioned into three shapes, namely a sphere that has a radius of $10 \mathrm{~mm}(\mathrm{G} 2)$, a tube that has a height and radius of $5 \mathrm{~mm}(\mathrm{G} 3)$, and a part that builds a space with one of its curved surfaces related to the radius of the ball and the tube radius (G4). In order to determine the building space where one of its surfaces is curved using an integral concept, students think of making an image in two dimensions (G5). Students experience a scheme gap (SG1) between images on two dimensions with the aim of determining the function or equation contained in the integral form (G6).

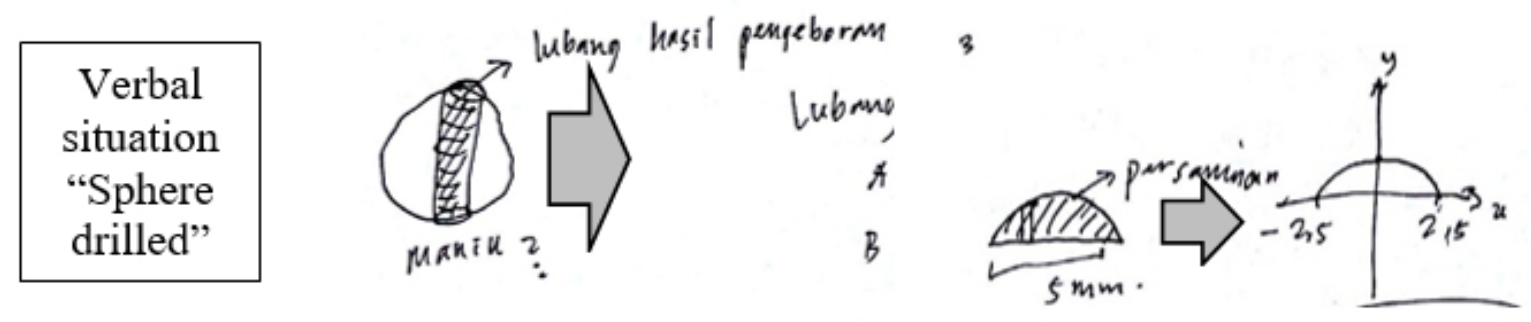

Figure 2. S3 draws Sphere drilled into Cartesian diagram.

The gap between schemes that occurs stimulates students to create new representations (target representations). In this case, the planned preliminary coordination is to sketch graphs on the Cartesian plane. The student then constructs the target by making the Cartesian diagram first (G7) then drawing a space with one of its curved surfaces in the Cartesian diagram (G2) with centre (0.0) (G8) and the radius of the drill bit $5 \mathrm{~mm}$ (G9). Through the results of the construction, the students produced a drawing of the remaining space with one curved surface cantered at point $(0,0)(\mathrm{G} 10)$.

The graphs made by students actually still leave a gap between the existing facts or the gap between schemes (SG2) but the gap is not realized by students. Student awareness (low awareness) results in students not correcting doing the process of determining equivalence or restructuring of the representation made of the target. Another thing that is a cause is the low sense of geometry of the students where they do not consider the facts that exist in the representation of sources, such as the radius of the ball and tube that should be adjusted with the graph. In this context, students have experienced structural fragmentation of translation thinking from verbal (the problem of the ball being drilled) with a graph (drawing of a ball being drilled in the Cartesian plane).

\section{Fragmentation of Translations Thinking Structure from Graphical to Symbolic Representation}

Students are aware of the fragmentation of the structure of translational thinking after researchers invite students to reflect by providing limited interventions. The process that occurs is as follows: 


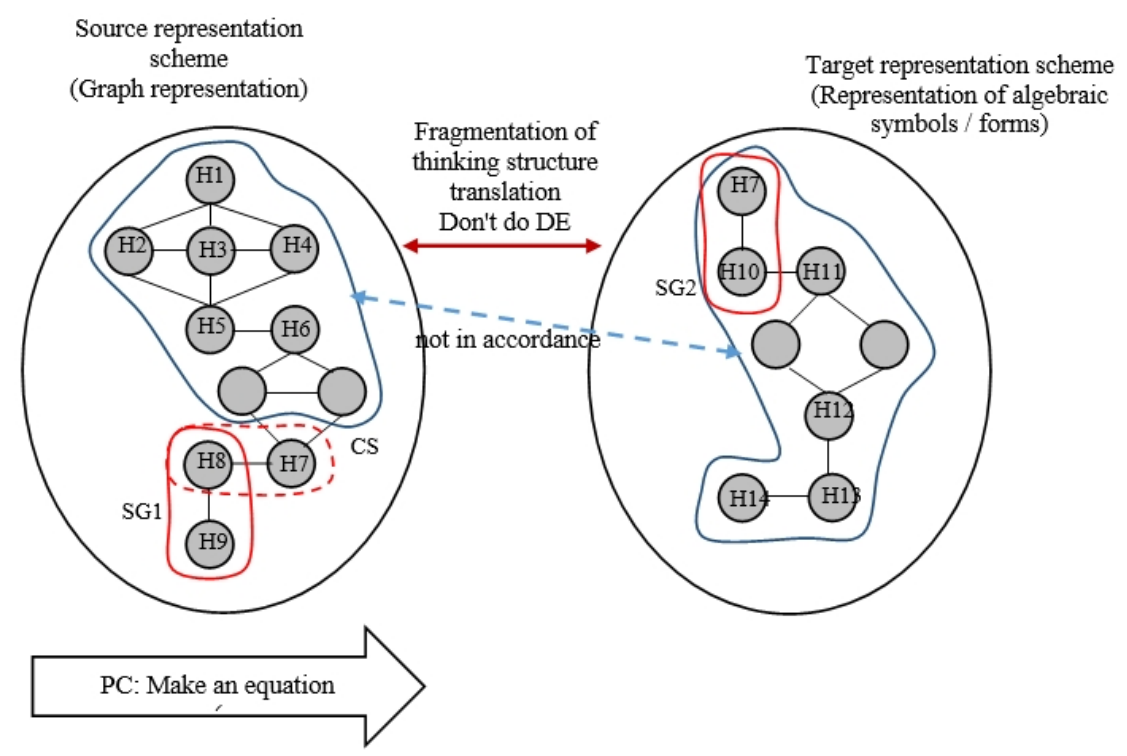

Figure 3. Illustration of Structure Fragmentation Thinking of Translations from Graph Representation to Symbols (Algebraic Forms).

Students initially make ball graphs drilled in two dimensions (H5). The first time, students think about the existence of a ball that is drilled (H1), then they mention that the build formed from drilling the ball $(\mathrm{H} 2)$, the tube (H3), and the space with one of its curved surfaces (H4). Students draw a ball drilled in the Cartesian plane (H6) in which there are $X$ and $Y$ axes. Students focus on the curved structure for drawing on the Cartesian plane (H7). Students understand that the result is like a bowl (H8) and students say they will make an equation from the picture. In this case, there is a gap between schemes (SG1) which results in students having a reason to make an equation or make a new representation of the created image. Before students determine the equation, students experience co-founding schemes or ambiguity schemes (CS) between the curves with a bowl shape. The ambiguity is an error of assumptions built by students that affect the making of new equations or representations.
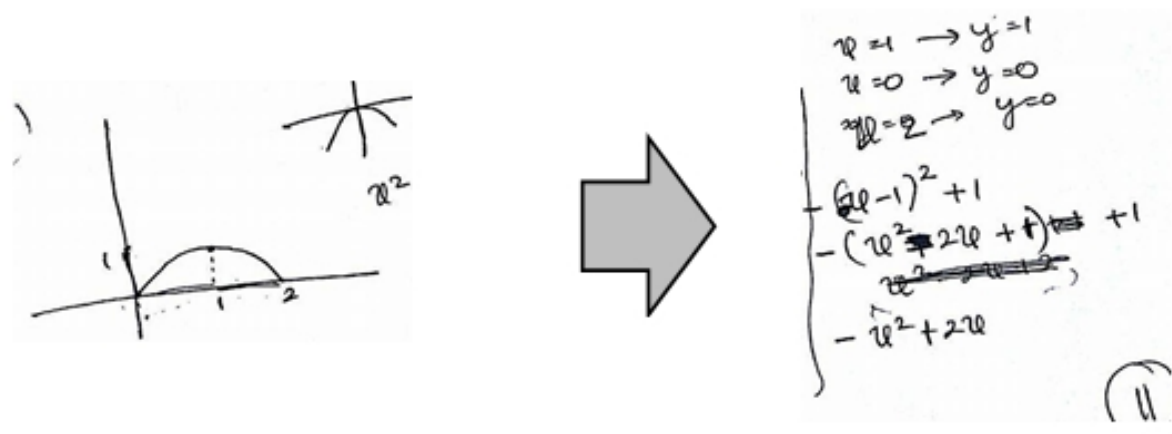

Figure 4. S2 creates a quadratic equation from the Cartesian diagram

Students focus on the curved shape in the created Cartesian diagram. Students assume that the shape is like a bowl (H7) so that it can be seen as a quadratic function (H10). Students then test the intersection, such at $y=0$ and $x=0$ (H11). Then do the substitution (H12) in the formula of the quadratic equation that has been determined, namely $y=a\left(x-x_{1}\right)^{2}-x_{2}$ 
(H13). Based on these results, students determine the quadratic equation, $y=-x^{2}+2 x$ (H14). After finding these equations, students did not directly perform equivalent equivalence or restructuring on the representation of the target. Whereas in the representation of the constructed target there is still a gap between the schemes (SG2) which is between a curved shape which is assumed to be a bowl with a quadratic function. In this case, students experience structural fragmentation of translation thinking from graphical representation to symbolic representation (algebraic form) caused by superficial student assumptions about the graphs made and their low understanding of quadratic functions.

\section{Fragmentation of Thinking Structure Translations from Graph and Symbol Representations (Algebraic Forms) to Mathematical Models}

Students are aware of the fragmentation of the structure of translational thinking after researchers invite the students to reflect by providing limited interventions. The process that occurs is as follows:

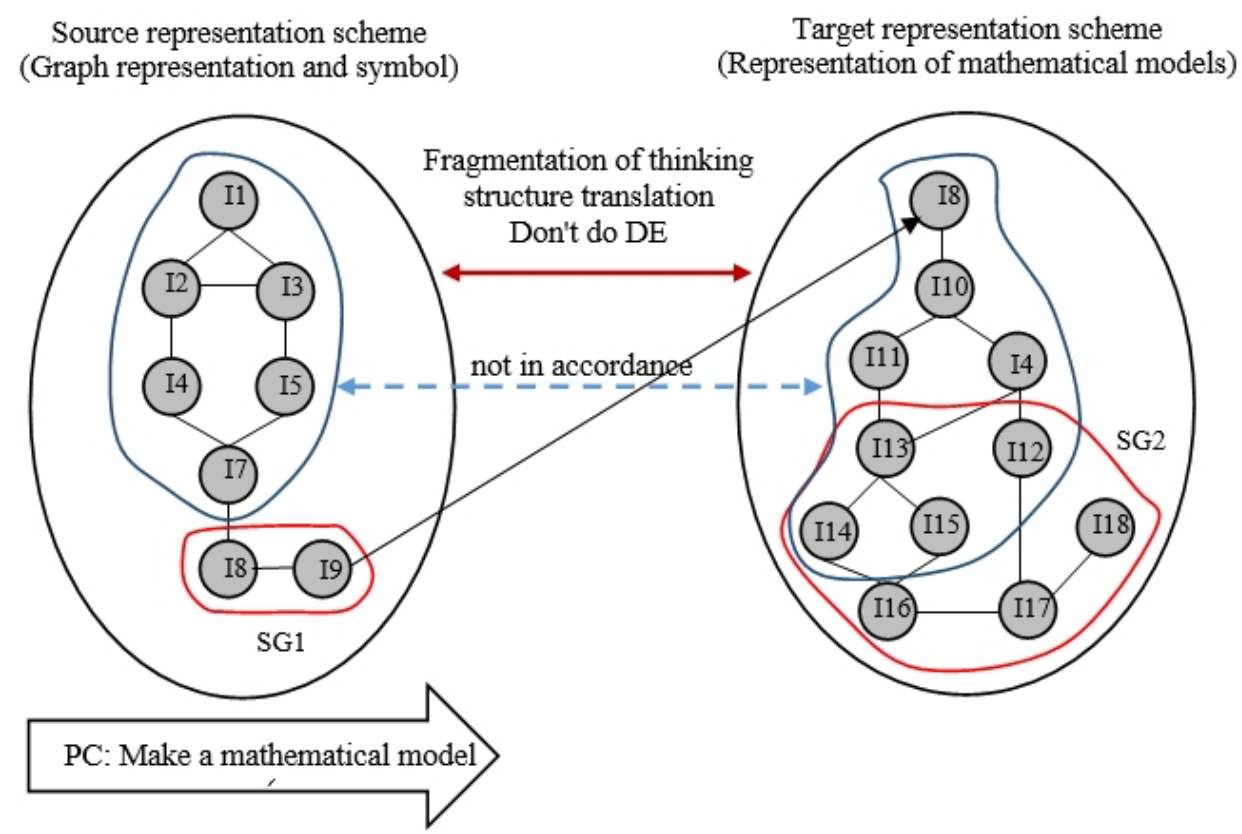

Figure 5. Illustration of Fragmentation of Translations Thinking Structure from Graphical and Symbolic to Mathematical Models (Integral Forms).

Students initially construct their ideas which are referred to as a collection of micro concepts in the source representation. In the source representation, there are graphs and symbols or equations of circles. Through the scheme formed on the source representation, there is a gap between schemes (SG1) which stimulates students to create new representations. The process that occurs is as follows.

Students initially draw the ball drilled in the Cartesian diagram in the direction of the $\mathrm{Y}$ axis (I1). From the results of the drilling, students pay attention to the circle image which is seen as a graph (I2) and the drill bit that crosses the circle (I3). Students determine the equation of the circle (I4) and the radius of the drill bit $5 \mathrm{~mm}$ (I5). From the similarities and radii of the drill bit, students focus on the remaining part of the drilling results (I7). Students think about 
solving the problem using integrals. Then the student determines the integration area (I8) and thinks of making an integral form (I9). In this case, there has been a gap between the schemes (between I8 and I9) (SG1). The gap between these schemes stimulates students to make new representations. Students do preliminary coordination by planning to create mathematical models or of course integral forms.

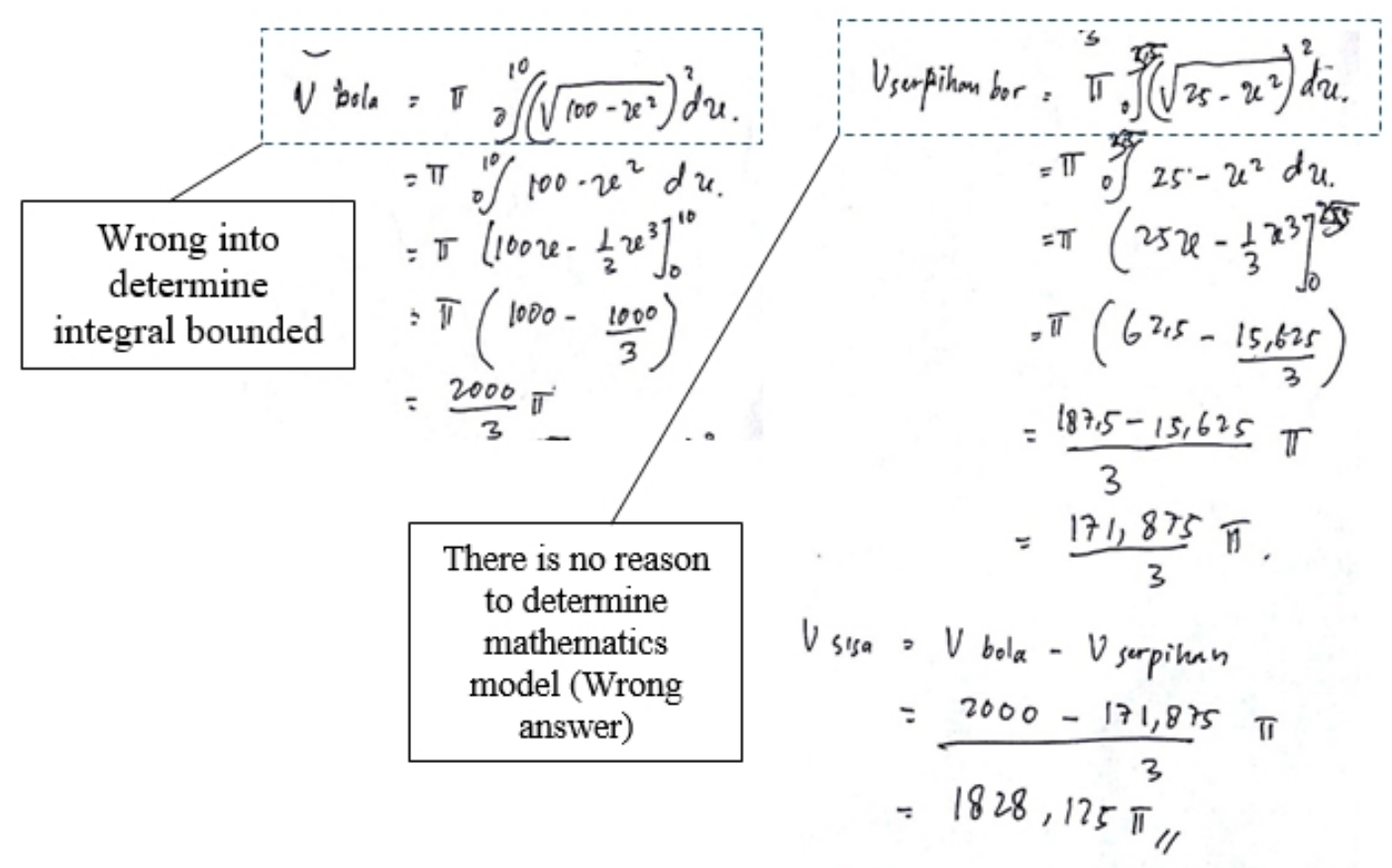

Figure 6. S3 created mathematics model by integration from verbal situation, graph, and algebraic forms.

Students begin to construct new representations by focusing on the integrated integration area (I8). The integrated area is in the form of building up the remaining drilling results (I10). Students use the equation of the circle that is $x^{2}+y^{2}=25$ (I4) and change it in the form $y=\sqrt{25-x^{2}}$ (I12). Students think of integration limits (I13), namely, the lower limit $=0$ (I14) and the upper limit $=5$ (I15). Circle equations and predetermined boundaries are then used as the basis for creating a mathematical model (integral form) (I16). The result of the substitution is $\int_{0}^{5} y^{2} d x$ (I17) $=\int_{0}^{5}\left(25-x^{2}\right) d x$ (I18). In determining the mathematical model, students are not able to justify the existence of boundaries, or the functions $y^{2}$, and $d x$. Students only say that it is "usually like that" to create an integral form of the volume of a rotating object. The new representation made by students is not in accordance with the representation of the appropriate source. When viewed from the scheme that has been constructed, there are still gaps between the schemes which results in errors. In this case, students experience the fragmentation of the structure of translational thinking from graphs and symbols to mathematical models (integral forms). Students do not do determination equivalence or restructuring of the scheme on new representations or targets because students are not aware of the mistakes they have made and their understanding of determining the integral form has no strong basis. 


\section{Conclusion}

Based on the results of the research and discussion, it can be concluded that the characteristics of the translation structure's fragmentation of thinking appear when students make mistakes in changing the old representations (source representation) to new representations (target representation). Errors that occur can be seen in the construction of the scheme of the new representations and the old representations. The construction error is named as confounding schemas or schemes that are ambiguously constructed. There are three fragmentations of the structure of translation thinking in solving mathematical problems, namely: fragmentation of translation thinking structure from verbal representation to graphical, fragmentation of translation thinking structure from graphical to symbolic, and fragmentation of the structure of translation thinking from graphical and symbolic to mathematical model representations. Each fragmentation that occurs basically has the same characteristics. It's just that there are different processes, especially when doing coordination preliminary and constructing the target.

\section{Acknowledgements}

I wish to express my thanks for the guidance and support that I received from my main supervisor Prof. Dr. Toto Nusantara, my second supervisor Dr. Subanji, and my third supervisor Dr. I Nengah Parta. Also I want to express my deepest thanks of the sponsorship from Mr. Tony Barry of Australia, LPDP, and the Universitas Mahasaraswati Denpasar.

\section{References}

Booth, J.L., Barbieri, C., Eyer, F., \& Pare-Blagoev, E.J. (2014). Persistent and Pernicious Errors in Algebraic Problem Solving. Journal of Problem Solving, 7, 10-23. http://dx.doi.org/10.7771/1932-6246.1161.

Bosse, M.J., Adu-Gyamfi, K., \& Chandler, K. (2014). Students' Differentiated Translation Processes. International Journal for Mathematics Teaching and Learning. 1-28. Retrieved from http://www.cimt.plymouth.ac.uk/journal/default.htm.

Bossé, M.J., Adu-Gyamfi, K., \& Cheetham, M. (2011). Assessing the Difficulty of Mathematical Translations: Synthesizing the Literature and Novel Findings. International Electronic Journal of Mathematics Education, 6(3), 113-133.

Cobb, P., Yackel, E., \& Wood, T. (1992). A Constructivist Alternative to the Representational View of Mind in Mathematics Education. Journal for Research in Mathematics Education, 23(1), 2-3.

Creswell, J.W. (2007). Qualitative Inquiry and Research Design. Choosing among Five Approaches (2nd ed.). Thousand Osks, CA: Sage.

Dorko, A. (2011). Calculus Student' Understanding of Area and Volume in Non-Calculus Context. Unpublished Masters Thesis, University of Maine at Orono.

Kaput, J.J. (1987). Representation Systems and Mathematics. Janvier (Ed.), Problems of Representation in Teaching and Learning Mathematics, (19-26). Hillsdale, NJ: Erlbaum.

Kiat, S.E. (2005). Analysis of Student' Difficulties in Solving Integration Problems. The Mathematics Educator, 9(1), 39-59.

Moleong, L.J. (2007). Metodologi Penelitian Kualitatif [Qualitative Research Methodology]. Bandung: PT Remaja Rosdakarya Offset. 
Musser, G.L., Burger, W.F., \& Peterson, B.E. (2011). Mathematics for Elementary Teachers a Contemporary Approach, Ninth Edition. United States of America: John Wiley \& Sons, Inc.

Serhan, D. (2015). Students' Understanding of the Definite Integral Concept. International Journal of Research in Education and Science (IJRES), 1(1), 84-88.

Skemp, R.R. (1976). Relational Understanding and Instrumental Understanding. Mathematics Teaching, (online), 77, 20-26. Retrieved from https://alearningplace.com.au/wp-content/uploads/2016/01/Skemp-paper1.pdf.

Skemp, R.R. (1982). Psychology of Learning Mathematics, 2nd Edition. London: Penguin Books.

Skemp, R.R. (2006). Relational Understanding and Instrumental Understanding. Mathematics Teaching in the Middle School, 12(2), 88-95.

Sternberg, R.J., \& Sternberg, K. (2012). Cognitive Psychology, Sixth Edition. USA: Wadsworth Cengage Learning.

Subanji. (2015). Teori Kesalahan Konstruksi Konsep dan Pemecahan Masalah Matematika [Error Theory Construction Concepts and Mathematical Problem Solving]. Malang: Universitas Negeri Malang (UM Press).

Subanji. (2016). Teori Defragmentasi Struktur Berpikir dalam Mengonstruksi Konsep dan Pemecahan Masalah Matematika [Defragmentation Theory of Structure of Thinking in Constructing Concepts and Solving Mathematical Problems]. Malang: Universitas Negeri Malang (UM Press).

Veloo, A., Krishnasamy, H.N., \& Abdullah, W.S.W. (2015). Types of Student Errors in Mathematical Symbols, Graphs, and Problem-Solving. Asian Social Science, 11(15), 324-334.

Wahono, R.S. (2009). Defragmentasi Otak: Cara Cerdas menjadi Cerdas [Brain Defragmentation: The Smart Way to Be Smart]. Universitas Bangka Belitung. Retrieved from http://www.ubb.ac.id/ menulengkap.php? judul=Defragmenting\%20Otak\%20:\%20Cara\%20Cerdas\%20Menjadi\%20Cerdas\&\&no morurut_artikel $=380$.

Wibawa, K.A., Subanji, \& Chandra, T.D. (2013). Defragmenting Berpikir Pseudo dalam Memecahkan Masalah Limit Fungsi [Defragmenting Pseudo Thinking in Solving Function Limit Problems]. Seminar Nasional Exchange of Experiences Teachers Quality Improvement Program (TEQIP). Malang: Universitas Negeri Malang.

Yin, R.K. (2011). Qualitative Research from Start to Finish. New York: The Guilford Press.

Yost, D. (2009). Integration: Reversing Traditional Pedagogy. Australian Senior Mathematics Journal, 22, 37-40.

Zakaria, E., Ibrahim, \& Maat, S.M. (2010). Analysis of Students' Error in Learning of Quadratic Equations. International Education Studies, 3(3), 105-110. 
Fragmentation of the Thinking Structure of

Translation in Solving Mathematical Modelling Problems 